\title{
Effect of nicardipine on somatosensory evoked potentials in patients with acute cerebral infarction
}

\author{
Liping Yao, Deyun Ding
}

\begin{abstract}
We evaluated the effect of nicardipine, a calcium channel blocker, on somatosensory evoked potentials (SEP) in 26 patients with acute cerebral infarction. Post treatment, $58 \%(15 / 26)$ of the N20 and P25 latencies were prolonged in the affected hemispheres; $8 \%(2 / 26)$ were shortened; and $35 \%(9 / 26)$ did not change. The mean N20 and P25 latencies were significantly prolonged two hours post treatment in the affected hemisphere (N20, P $<0.01$, P25 P $<0.01)$. Nicardipine (Ni) had no effect on SEP components in the intact hemispheres. Seventy five per cent of the 12 patients with hypertension had a decrease in blood pressure (BP) after taking nicardipine, but there were no undesirable side effects or worsening of neurological signs. Our study demonstrates that nicardipine prolongs the latencies of short-latency components of SEP in the affected hemisphere after acute ischaemic stroke and also decreases BP. These observations suggest that nicardipine therapy might impair neuronal function in the ischaemic zone.
\end{abstract}

Most studies evaluating the protective effect of $\mathrm{Ca}++$-antagonists on acute ischaemic stroke have been carried out on animal models. Only a few clinical studies have been reported and these results have been variable. ${ }^{1}$ We evaluated the effect of nicardipine, a dihydropyridine calcium antagonist, on electrocerebrophysiological function in patients with acute cerebral infarction by means of somatosensory evoked potentials (SEP). The technique has been used in animal and human studies as a possible index of neuronal function after acute ischaemic stroke. ${ }^{23}$

Department of Neurology, Second Affiliated Hospital of Zhejiang Medical University, Hangzhou, Zhejiang, People's Republic of China L Yao

D Ding

Correspondence to:

Dr L Yao, University of

Pittsburgh Medical School,

Anesthesia and CCM

Research Laboratories,

1081 Scaife Hall, Pittsburgh,

PA 15261, United States.

Received 5 October 1989

and in revised form

3 January 1990.

Accepted 18 January 1990

Materials and methods
Twenty six patients were included in the study. All patients had suffered their first acute cerebral infarction. There were 18 males and eight females, aged 50-78 years (mean: 64). All patients had CT scans within 10 days post-stroke. The maximal diameter of lesions on CT ( $8 \mathrm{~mm}$ slices) were as follows: $1 \mathrm{~cm}: 22$

Table 1 Post-stroke interval for SEP recordings patients, $2 \cdot 5-5 \mathrm{~cm}$ : two patients, normal CT: two patients. Internal capsule: 10 patients, parietal lobe: nine patients, frontal lobe: two patients, basal ganglia: two patients, thalamus: one patient. No patient was shown to have more than one infarct. All patients were conscious and had clinical manifestations of hemispheric involvement.

Needle electrodes were placed in Fpz, C3 and $\mathrm{C4}^{\prime}$ ( $2 \mathrm{~cm}$ behind standard EEG C3 and C4), and the stimulating electrode was fixed to the skin over the median nerve at the wrist (electrode impedance $5 \mathrm{~K}$ ). Stimuli were 0.2 ms square wave electrical pulses delivered with a frequency of $5 \mathrm{~Hz}$ and an intensity just above the thumb twitch threshold (current intensity 5-15 mA). The peak latencies of N20 and P25 components in the intact and affected hemispheres were recorded. At least three series of 256 responses were averaged for each side. The range of variability within individuals was less than $0.4 \mathrm{~ms}$.

All patients had SEP examinations and 12 patients had blood pressure (BP) measured (cuff method) before and two hours after they had one $40 \mathrm{mg}$ oral dose of nicardipine. Measurements were carried out between 24 hours and seven days post-stroke (table 1 ). No other vasoactive drugs were given at the time of SEP and BP recordings. The N20 and P25 latencies and $\mathrm{BP}$ before and after treatment were analysed by paired Student's $t$ test.

\section{Results}

1 Effect of nicardipine on SEP (table 2)

Fifty eight per cent (15/26) of the N20 and P25 latencies were prolonged in the affected hemispheres, $8 \%(2 / 26)$ were shortened, and $35 \%(9 / 26)$ did not change post-treatment. The mean N20 and P25 latencies post-treatment were statistically significantly longer than pre-treatment in the affected hemispheres (N26 P $<0.01$, P25 P $<0.01)$. There was no effect of nicardipine on SEP latencies in the intact hemispheres.

\section{Effect of nicardipine on BP (table 3)}

Two hours after receiving nicardipine, $75 \%$ of the 12 patients with hypertension had a decrease in BP. A statistically significant decrease in both systolic and diastolic pressures were observed.

\begin{tabular}{lllllll}
\hline Day & $24 h r s-2 n d$ & $2 n d-3 r d$ & $3 r d-4 t h$ & $4 t h-5 t h$ & $5 t h-6 t h$ & $6 t h-7 t h$ \\
\hline Number of patients & 5 & 8 & 3 & 2 & 2 & 6 \\
\hline
\end{tabular}


Table $2 \quad N 20$ and P25 latencies ( $m s$ ) in affected and intact hemispheres before and after nicardipine

\begin{tabular}{|c|c|c|c|c|c|}
\hline & \multirow[b]{2}{*}{$S E P$} & \multirow[b]{2}{*}{$N$} & \multicolumn{2}{|l|}{$\operatorname{Mean}(S D)$} & \multirow[b]{2}{*}{$P$} \\
\hline & & & Before nicardipine & 2 hours after nicardipine & \\
\hline Affected hemisphere & $\begin{array}{l}\text { N20 } \\
\text { P25 }\end{array}$ & $\begin{array}{l}26 \\
26\end{array}$ & $\begin{array}{l}20.13(1.45) \\
26.31(1.99)\end{array}$ & $\begin{array}{l}21.80(2.08) \\
28.00(1.99)\end{array}$ & $\begin{array}{l}<0.01 \\
<0.01\end{array}$ \\
\hline Intact hemisphere & $\begin{array}{l}\text { N20 } \\
\text { P25 }\end{array}$ & $\begin{array}{l}26 \\
26\end{array}$ & $\begin{array}{l}19.78(1.26) \\
26.68(1.87)\end{array}$ & $\begin{array}{l}19.88(1.33) \\
26.29(1.84)\end{array}$ & $\begin{array}{l}>0.05 \\
>0.05\end{array}$ \\
\hline
\end{tabular}

\section{Effect of nicardipine on clinical} manifestations

No undesirable side effects occurred and no patient had neurological deterioration after receiving nicardipine.

\section{Discussion}

The short-latency components of the SEP are closely related to neuronal metabolism and cerebral blood flow. Neuronal damage may result in abnormalities of the SEP such as prolonged latency, lowered amplitude, and even complete absence of the components. ${ }^{4}$ $\mathrm{N} 20$ and P25 waves are short-latency components of the SEP reflecting impulses transmitted to the thalamus and reaching the cortex through the primary sensory system. The N20 component may originate from thalamus, thalamocortical projections, or the primary sensory cortex. ${ }^{56}$ Absence or asymmetry of short-latency components of the SEP have been reported in $50 \%-75 \%$ of lacunar infarcts ${ }^{78}$ and such abnormalities have been particularly notable in thalamic infarcts or pure sensory stroke. ${ }^{3}$

Nicardipine is a potent second generation dihydropyridine calcium channel blocker. Plasma concentration of the drug is highest 20 minutes after administration, and $B P$ is maximally decreased after two hours. ${ }^{910}$ This hypotensive effect has limited the amount of nicardipine which can be given in animal and. human stroke studies. ${ }^{211}$ Grotta et $a l^{2}$ evaluated the effect of nicardipine on the SEP in rats after four-vessel occlusion. The amplitude but not latency of short-latency components of the SEP were improved in treated animals, and CBF increased during reperfusion.

In animal studies, if $\mathrm{Ca}++$-antagonists were given pre-ischaemia or immediately post-ischaemia, outcome measures such as histology, cerebrospinal fluid (CBF), electrophysiological function, learning ability, brain oedema, and mortality were often improved. However, when given post-ischaemia, the protective effect of $\mathrm{Ca}++$-antagonists was absent and even negative results were observed. ${ }^{212-30}$ Although Vorstrup et al found that nimodipine actually decreased cerebral blood flow (CBF) in the area of infarction in patients with acute ischaemic stroke, ${ }^{31}$

Table 3 The effect of nicardipine on blood pressure ( $\mathrm{mm} \mathrm{Hg}$ )

\begin{tabular}{llll}
\hline \multicolumn{4}{c}{ Mean $(S D)$} \\
\hline $\mathrm{N}$ & Before nicardipine & 2 hours after nicardipine & P \\
12 & $168 / 98(14 / 10)$ & $148 / 88(22 / 12)$ & $<0.01$ \\
\hline
\end{tabular}

Gelmers et $a l^{32}$ reported that recovery of patients receiving oral nimodipine started up to 24 hours after acute ischaemic stroke was better than in control patients.

Our results suggest that nicardipine possibly aggravated neuronal dysfunction in the affected hemisphere of patients when given one to seven days after ischaemic stroke. This result may have several explanations: 1) intracerebral "steal" of blood from ischaemic brain regions to areas of normal vascular reactivity where nicardipine causes vasodilation; 2) reduced $C B F$ due to reduced $B P$ and cerebral perfusion pressure; and 3) nicardipine therapy may have been given too late after stroke to reverse a transient ischaemic penumbra, or effectively limit calcium influx and its intracellular translocation.

In conclusion, our studies suggest that: 1) nicardipine prolongs the latency of SEP shortlatency components in ischaemic hemispheres when given one to seven days after acute ischaemic stroke, and also decreases BP; and 2) SEP measures might be useful as a convenient means to evaluate the effect of therapy on electrophysiological function and to provide a quantitative outcome measurement for clinical studies.

According to the results in the literature, we consider that it is possible that patients with acute infarction might benefit from treatment with a calcium antagonist if treatment could be given before onset of the symptoms or within 24 hours after incident. The therapeutic use of calcium antagonist in acute ischaemic stroke needs more extensive experimental studies in various stroke models and clinical documentation in large-scale double-blind studies.

The authors acknowledge the critical review of James $C$ Grotta, Associate Professor of Neurology, Department of Neurology, The University of Texas Medical School, Houston. Drs Yangda Zhang, Yuanshen Zheng and Jianzheng Huang reviewed the manuscript and provided helpful comments.

This study was supported by grants from Zhejiang Medical University and Bao Yukong and Bao Zaolong Scholarships.

1 Greenberg DA. Calcium channel antagonists: pharmacolog and neurological applications. In: Appel SA, ed. Curren Neurology Vol 6. London: Year Book Medical Publishers, 1986:91-123.

2 Grotta JC, Spydell J, Pettigrew C, Ostrow P, Hunter D. The effect of nicardipine on neuronal function following ischemia. Stroke 1986;17:213-9.

3 Robinson KR, Richey ET, Kase CS, Mohr JP. Somatosensory evoked potentials in pure sensory stroke and related conditions. Stroke 1985;16:818-23.

4 Ropper AH. Evoked potentials in cerebral ischemia. Stroke 1986;17:3-4.

5 Greenberg RP, Ducker TB. Evoked potentials in the clinical neurosciences. J Neurosurg 1982;56:1-8.

6 Chiappa KH, Ropper AH. Evoked potentials in clinical medicine. N Engl J Med 1982;306:1205-11. 
7 Abbruzzese G, Bino G, Agata DD, Morena M, Primavera A, Favale E. Somatosensory evoked potentials in lacunar syndromes. J Neurol 1988;235:300-3.

8 Hassel M, Hacke W, Ferbert A, Zeumer H, Krtochvil P. Electrophysiologic findings in lacunar infarcts. $E E G$ EMG 1986;17:83-7.

9 Sorkin EM, Clissold SP. Nicardipine. Drugs 1987;33: 296-345.

10 Iliopoulou A, Turner P, Warrington SJ. Acute haemodynamic effect of a new calcium antagonist, nicardipine, in man A comparison with nefedipine. Br J Clin Pharmac 1983;15:59-65.

11 Grotta JC, Rosenbaum D, Zabramski J, et al. Pilot study of nicardipine (NC) for acute stroke. Neurol 1988;38 (Suppl 1): 109 .

12 Reempts JV, Deuren VB, Ven VM, Cornelissen F, Borgers $M$. Ischemic brain injury and cell calcium, morphologic and therapeutic aspects. Ann Emerg Med 1985;14:736-42.

13 Mabe H, Nagai H, Takagi T, Umemura S, Ohno M. Effect of nimodipine on cerebral functional and metabolic recovery following ischemia in the rat brain. Stroke 1986;17:501-5

14 Bielenberg GW, Beck T, Sauer D, Burniol M, Krieglstein J. Effect of cerebroprotective agents on cerebral blood flow and on postischemic energy metabolism in rat brain. $J$ Cereb Blood Flow Metab 1987;7:480-8.

15 Reempts JV, Deuren BV, Ven MV, Cornelissen F, Borgers $M$. Flunarizine reduces cerebral infarct size after photochemically induced thrombosis in spontaneously hypertensive rats. Stroke 1987;18:1113-9.

16 Alps BJ, Hass WK. The potential beneficial effect of nicardipine in a rat model of transient forebrain ischemia. Neurol $1987 ; 37: 807-14$

17 Harris RJ, Branston NM, Symon L, Bryhan M, Watson A. The effect of a calcium antagonist, nimodipine, on physiological response of the cerebral vasculature and its possible influence upon focal cerebral ischemia. Stroke 1982;13:759-66.

18 Sauter A, Rudin M. Calcium antagonists reduce the extent of infarction in rat middle cerebral artery occlusion model as determined by quantitation magnetic response imaging. Stroke 1986;17:1228-34.

19 Bederson JB, Bartkowski HM, Obana W, Mishimura MC T'suji M, Pitts JH. Nimodipine in rat middle cerebral occlusion. Stroke 1985;16:142.
20 Newberg LA, Steen PA, Milde JH, Michenfelder JD. Failure of flunarizine to improve cerebral blood flow or neurologic recovery in a canine mode

21 Dean JM, Hoehner PJ, Rogers MC, Traystman RJ. Effect of idoflazine on cerebral blood flow following twelve minutes total cerebral ischemia. Stroke 1984;15:531-5.

22 Sakabe T, Nagai I, Ishikawa T, et al. Nicardipine increase cerebral blood flow but does not improve neurologic recovery in a canine model of complete cerebral ischemia. $J$ Cereb Blood Flow Metab 1986;6:684-90.

23 Gotoh O, Mohamed AA, McCulloch J, Graham DI, Harper AM, Treasdale GM. Nimodipine and the haemodynamic and histopathologic consequences of middle cerebral and histopathologic consequences of middle cerebral artery occlusion

24 Vibulsresth S, Dietrich WD, Busto R, Ginsberg MD Failure of nimodipine to prevent ischemic neuronal damage in rats. Stroke 1987:18:210-16.

25 Steen PA, Gisvold SE; Milde JH, et al. Nimodipine improves outcome when given after complete cerebral ischemia in primates. Anesthesiology 1985;62:406-14.

26 Kucharczyk J, Chew W, Nikita D, et al. Nicardipine reduce ischemic brain injury-magnetic response imaging spectroscopy study in cats. Stroke 1989;20:268-74.

27 Kobayashi S, Obana W, Andrews BT, Nisimara MC, Pitts LH. Lack of effect of nimodipine in experimental regional cerebral ischemia. Stroke 1988;19:147.

28 Germano IM, Burris SM, Smith CMII, Rao GHR, White JG. The therapeutic value of nimodipine in experimental fo. The therapeutic value of nimodipine in exper

29 Barnett GH, Bose B, Little JR, Jones SC, Friel HT. Effects of nimodipine on acute focal cerebral ischemia. Stroke 1986;17:884-90.

30 Grotta JC, Pettigrew LC, Rosenbaum D, Reid C, Rhoade $\mathrm{H}$, McCandles D. Efficacy and mechanism of action of calcium channel blocker after global cerebral ischemia in rats. Stroke 1988;4:447-54.

31 Vorstrup S, Andersen A, Blegvad N, Paulson OB. Calcium antagonist (PY 108-068) treatment may further decrease flow in ischemic areas in acute stroke. J Cereb Blood Flow Metab 1986;6:222-9.

32 Gelmers HJ, Gorter K, Weerdt CJ, Wiezer HJ. A controlled trial of nimodipine in acute ischemic stroke. $N$ Engl J Med 1988;318:203-7. 